\title{
POTENCIAL DE RENDIMENTO DE GRÃOS E OUTRAS CARACTERÍSTICAS AGRONÔMICAS E TECNOLÓGICAS DE NOVOS GENÓTIPOS DE TRIGO ${ }^{\left({ }^{1}\right)}$
}

\author{
JOÃO CARLOS FELÍCIO $\left({ }^{2}\right)$; CARLOS EDUARDO DE OLIVEIRA CAMARGO $\left({ }^{2}\right)$; JOSÉ CARLOS \\ VILA NOVA ALVES PEREIRA $\left({ }^{3}\right)$; ROGÉRIO GERMANI $\left({ }^{4}\right)$; PAULO BOLLER GALLO $\left({ }^{5}\right)$; JAIRO \\ LOPES DE CASTRO $\left({ }^{6}\right)$; ANTONIO WILSON PENTEADO FERREIRA FILHO $\left({ }^{2}\right)$
}

\begin{abstract}
RESUMO
Estudou-se o comportamento de 17 novos genótipos de trigo (Triticum aestivum L.) tendo como testemunha as cultivares IAC 370, IAC 289 e IAC 350 em experimentos semeados em dois sistemas de cultivo, sequeiro: Capão Bonito e Itapeva, e irrigação por aspersão: Paranapanema, Ribeirão Preto e Mococa, no período de 2001 a 2002, no Estado de São Paulo. Avaliaram-se os rendimentos de grãos de cada genótipo em relação às diferentes condições de cultivo, tolerância ao alumínio com o emprego de soluções nutritivas, reação às principais doenças fúngicas e a qualidade tecnológica da farinha. Destacaram-se, na média geral, quanto ao rendimento de grãos os genótipos ALD/CEP76630//CEP73234/PF7219/3/BUC"S" / BYJ"S" e MARNG/BUC"S" / /BLO"S" /PSN"S" /3/BUC/PVN"S", em cultivo de sequeiro e com irrigação por aspersão, respectivamente. Os genótipos CNO79/PRL"S"//IAC 227 e RAC 646/BH 1146 foram tão tolerantes à toxicidade de $\mathrm{Al}^{3+}$ quanto a cultivar tolerante BH 1146. A incidência da ferrugem-da-folha não foi constatada nos genótipos CHAT"S" / CEP7780/ / PRL"S" / BOW"S'", SABUF, WG 3070/2*WEAVER e ALDAN"S" /IAS 58//IAC 60 que foram imunes à doença, no biênio em estudo, em ambos os sistemas de cultivo. Todos os genótipos foram suscetíveis aos agentes causais das manchas foliares. A qualidade tecnológica das amostras de farinhas procedentes de Capão Bonito, Região Sudoeste, foram superiores às obtidas em Ribeirão Preto, Região Central do Estado São Paulo.
\end{abstract}

Palavras-chave: trigo, novos genótipos, rendimento de grãos, tolerância ao alumínio, reação às doenças, qualidade tecnológica da farinha.

\section{ABSTRACT \\ GRAIN YIELD POTENCIAL AND AGRONOMIC AND TECHNOLOGIC CHARACTERISTICS OF NEW WHEAT GENOTYPES}

Seventeen new wheat (Triticum aestivum L.) genotypes and the control cultivars IAC 370, IAC 289 and IAC 350 were evaluated in experiments carried out in two cultivation systems, upland: Capão Bonito and Itapeva, and with sprinkler irrigation: Paranapanema, Ribeirão Preto e Mococa, during the years of 2001 and 2002, in the State of São Paulo, Brazil. Grain yield of each genotype in both cultivation systems, aluminum tolerance in nutritious solutions, reaction to the main fungic diseases and the technologic

$\left({ }^{1}\right)$ Com apoio financeiro da FAPESP. Recebido para publicação em 13 de outubro de 2004 e aceito em 15 de março de 2006.

$\left({ }^{2}\right)$ Centro de Análise e Pesquisa Tecnológica dos Agronegócios de Grãos e Fibras, Instituto Agronômico (IAC), Caixa Postal 28, 13020-902 Campinas (SP). Autor correspondente. E-mail: jfelicio@iac.sp.gov.br; ccamargo@iac.sp.gov.br; ferreira@iac.sp.gov.br

$\left({ }^{3}\right)$ Pólo Regional de Desenvolvimento Tecnológico dos Agronegócios do Centro-Leste, APTA/DDD , Caixa Postal 271, $14001-970$ Ribeirão Preto (SP).

$\left({ }^{4}\right)$ Embrapa Alimentos, 23020-470 Rio de Janeiro (RJ). E-mail: germani@ctaa.embrapa.br

$\left(^{5}\right)$ Pólo Regional de Desenvolvimento Tecnológico dos Agronegócios do Nordeste Paulista, APTA/DDD, Caixa Postal 58, 13730-970 Mococa (SP).

( $\left.{ }^{6}\right)$ Pólo Regional de Desenvolvimento Tecnológico dos Agronegócios do Sudoeste Paulista, APTA/DDD, Caixa Postal 62, 18300-970 Capão Bonito (SP). 
flour quality were evaluated. The genotypes ALD/CEP76630 / /CEP73234/PF7219/3/BUC"S" /BYJ"S" and MARNG/BUC"S" / BLO"S" / PSN"S"/3/ BUC/PVN"S" showed good performance in upland and sprinkler irrigation system, respectively. The genotypes CNO79/PRL"S'//IAC 227 and RAC 646/BH 1146 were as tolerant to $\mathrm{Al}^{3+}$ toxicity as the tolerant cultivar BH 1146. CHAT"S" / CEP7780//PRL"S" / BOW"S'", SABUF, WG 3070/2*WEAVER and ALDAN "S"/IAS 58//IAC 60 genotypes were immune to the causal agent of leaf rust in the considered years and in both cultivation systems. All genotypes were susceptible to the causal agents of leaf spots. The technologic quality of the flour samples originated from Capão Bonito, Southeast region was superior to the ones from Ribeirão Preto, Central region of the State of São Paulo.

Key words: wheat, new genotypes, grain yield, aluminum tolerance, reaction to diseases, flour technologic quality.

\section{INTRODUÇÃO}

A partir do início dos anos oitenta, foram geradas pelo programa de melhoramento do trigo do Instituto Agronômico (IAC), Campinas, SP as cultivares IAC 21-Iguaçu, IAC 22-Araguaia, IAC 23-Tocantins. IAC 24-Tucuruí, IAC 74-Guaporé, IAC 28-Paracanã, IAC 161-Taiamã, IAC 162-Tuiuiú, IAC 25-Pedrinhas, IAC 27-Pantaneiro e IAC 60-Centenário (Felicio et al. 1983, 1984, 1985, 1988; Camargo e Felicio, 1986).

Felicio et al. (1992), avaliaram a produtividade de cultivares de trigo em duas diferentes regiões ecológicas paulistas, e concluíram que o regime hídrico das regiões foi importante para a produção de grãos: no Vale do Paranapanema (sequeiro), quando as chuvas foram bem distribuídas durante o ciclo contribuíram para o melhor desempenho da cultura; na Região Norte, a irrigação por aspersão, além de evitar a deficiência hídrica, propiciou rendimento elevado com baixos índices de doenças.

A tolerância ao crestamento, efeito primário da toxicidade de alumínio no trigo com paralisação do crescimento da raiz (KeRRIDGE, 1969), não é segundo MOORE et al. (1976), o único fator limitante em solos ácidos. Assim, os métodos de avaliação de plantas tolerantes e suscetíveis a determinado nível de alumínio com o emprego de soluções nutritivas podem tornar mais eficiente e precisa a separação dessas plantas em relação à tolerância ao alumínio (CAmargo e Oliveira, 1981).

Favorecidas por altas temperaturas e precipitações pluviais freqüentes, doenças como as ferrugens da folha e do colmo, induzidas respectivamente, por Puccinia triticina f.sp. tritici (Erikess) e P. graminis.f. sp. tritici (Herihs e Henn), a mancha da gluma induzida por Phaeosphaera nodorum, a mancha-marrom, induzida por Cochliobolus sativus (Bipolaris sorokiniana), a Giberela zeae (Fusarium graminearum), a brusone (Magnoporthe grisea), o carvão do trigo (Ustilago tritici), e, mais recentemente, a mancha-bronzeada da folha de trigo vêm preocupando triticultores, exigindo a realização de diversas aplicações de fungicidas de acordo com Picinini e FERNANDEs (2000).
O conceito de qualidade, em relação aos grãos de trigo, está intimamente relacionado com o destino industrial da farinha a ser produzida. A qualidade de determinado tipo de trigo não pode ser avaliada com base em um único parâmetro ou propriedade, pois não depende somente das características físicoquímicas do grão, mas também do sistema de moagem utilizado para a produção da farinha, das características físicas da massa e do processamento empregado para a obtenção do produto final (MANDARINO, 1993).

Este trabalho teve como objetivo apresentar uma análise da tendência da produtividade dos genótipos de trigo, em ambientes de cultivo de sequeiro e com irrigação por aspersão, sua relação com tolerância à toxicidade de alumínio, as reações às doenças e a qualidade tecnológica da farinha.

\section{MATERIAL E MÉTODOS}

O experimento foi realizado no Estado de São Paulo, no período de 2001/2002, nas seguintes localidades: Pólo Regional de Desenvolvimento dos Agronegócios do Sudoeste Paulista, no município de Capão Bonito e na Fazenda Palmeira do Ricardo em Itapeva, Zona tritícola B, em cultivo do trigo de sequeiro; na Fazenda Siloca, em Paranapanema, Zona tritícola C, nos Pólos Regionais de Desenvolvimento dos Agronegócios do Centro Leste (Ribeirão Preto), Zona tritícola G e no do Nordeste Paulista (Mococa), Zona tritícola $\mathrm{H}$, em cultivo com irrigação por aspersão. (Instituto Agronômico, 1999).

Foram avaliados 17 novos genótipos de trigo e as cultivares IAC 289, IAC 350 e IAC 370 utilizadas para comparação das médias de rendimento de grãos, reações às doenças e qualidade tecnológica da farinha, descritos na Tabela 1 . O delineamento experimental utilizado foi o de blocos ao acaso, com quatro repetições. As semeaduras foram efetuadas sempre no primeiro decêndio de abril nas condições de sequeiro e no primeiro e segundo decêndio de maio com irrigação por aspersão. As parcelas foram 
compostas por seis linhas de $3 \mathrm{~m}$ de comprimento, com espaçamento de $0,20 \mathrm{~m}$ entre si, e separação lateral de 0,60 m entre parcelas. Procedeu-se à semeadura com 60 sementes por metro linear de sulco, realizando-se a colheita na área total das parcelas, ou seja, 3,6 $\mathrm{m}^{2}$. As plantas foram mantidas livres de competição com plantas daninhas.

Antes da semeadura, a adubação foi feita a lanço, com posterior incorporação ao solo e consistiu na aplicação de 20, 60 e $28 \mathrm{~kg} \mathrm{ha}^{-1}$ de $\mathrm{N}, \mathrm{P}_{2} \mathrm{O}_{5}$ e $\mathrm{K}_{2} \mathrm{O}$ respectivamente, de acordo com RAIJ et al. (1996) e com a análise química do solo. Na adubação em cobertura, foram aplicados $40 \mathrm{~kg} \mathrm{ha}^{-1}$ de $\mathrm{N}, 20$ a 30 dias após a emergência das plântulas.

Nos experimentos irrigados, adotou-se o método proposto por SiLva et al. (1984), que consiste em uma irrigação de 40 a $60 \mathrm{~mm}$ após a semeadura, com a finalidade de umedecer o solo. As irrigações complementares foram realizadas quando a média das leituras dos tensiômetros, instalados em diversos pontos, à profundidade de $12 \mathrm{~cm}$, indicava $-0,6 \mathrm{MPa}$; determinou-se a lâmina líquida aplicada pela evaporação acumulada, medida no tanque classe A, entre os intervalos das irrigações .

O ciclo das cultivares foi determinado pelo número de dias decorridos da emergência das plântulas até a maturação. Os genótipos com ciclo da emergência à maturação de 110-120, 121-130 e acima de 130 dias foram considerados de ciclo precoce, médio e tardio respectivamente.

A altura das plantas foi medida em centímetros, no campo, na época de maturação, do nível do solo ao ápice da espiga, com exclusão das aristas, estimandose a média de diferentes pontos de cada parcela.

Avaliou-se o rendimento de grãos, em gramas, pesando a produção total de cada parcela, e transformando-a para quilograma por hectare.

$O$ rendimento de grão, de cada experimento foi submetido à análise de variância parcial (ano e local) e conjunta e a comparação das médias, feita mediante o teste de Duncan, (Pimentel-Gomes, 1970).

Tabela 1. Genealogia, ciclo em dias do período compreendido do início da germinação ao espigamento pleno (floração), do início da germinação a maturação fisiológica e a altura média das plantas dos genótipos de trigo avaliados em condição de sequeiro (Capão Bonito) e com irrigação por aspersão (R.Preto), no Estado de São Paulo, no período de 2001/2002

\begin{tabular}{|c|c|c|c|c|c|c|}
\hline \multirow{2}{*}{ Genótipos } & \multicolumn{3}{|c|}{ Capão Bonito } & \multicolumn{3}{|c|}{ Ribeirão Preto } \\
\hline & \multirow{2}{*}{\multicolumn{2}{|c|}{$\begin{array}{l}\text { Floraçao Maturaçao } \\
\text { dias }\end{array}$}} & Altura & Floração & Maturação & Altura \\
\hline & & & $\mathrm{cm}$ & \multicolumn{2}{|c|}{ dias } & $\mathrm{cm}$ \\
\hline 1-BOW"S" / GEN / / IAC 24 & 54 & 116 & 100 & 55 & 110 & 90 \\
\hline 2-MARNG / BUC"S" / / BLO"S" / PSN"S" / 3 / BUC / PVN"S" & 60 & 116 & 90 & 62 & 114 & 87 \\
\hline $3-\mathrm{F}_{3} 71 / \mathrm{TRM} / / \mathrm{CNO} 79 / 3 / \mathrm{IAC} 24$ & 54 & 116 & 100 & 59 & 110 & 84 \\
\hline 4-THB"S"/CEP 7780//BUC"S" & 54 & 127 & 80 & 55 & 125 & 75 \\
\hline 5 -IAC 370 & 71 & 135 & 90 & 64 & 133 & 88 \\
\hline 6-TEMU196.74/TANORI"S" / / IAC 24 & 47 & 116 & 90 & 55 & 114 & 83 \\
\hline 7- V.82178/IAC 24 & 47 & 110 & 85 & 55 & 105 & 75 \\
\hline 8-IAC 76/IAC 162 & 47 & 110 & 85 & 55 & 105 & 75 \\
\hline 9-NJ / PAK/ / CHAT / 3 / PRL"S" / ALD"S" & 69 & 130 & 93 & 64 & 128 & 86 \\
\hline 10-CHAT"S" / CEP 7780 / / PRL"S" / BOW"S" & 64 & 130 & 85 & 62 & 125 & 82 \\
\hline 11-ALDAN"S"/IAS58//IAC 60 & 64 & 116 & 100 & 59 & 110 & 88 \\
\hline 12-RAC 646/BH 1146 & 47 & 110 & 80 & 55 & 110 & 69 \\
\hline 13-SUPER X/6/R//IRN 471-63*5/7/IAC 24 & 54 & 116 & 85 & 57 & 112 & 70 \\
\hline 14-BAU"S"/BH 1146 & 54 & 127 & 100 & 55 & 110 & 76 \\
\hline 15-IAC 289 & 60 & 130 & 85 & 64 & 133 & 80 \\
\hline 16-IAC 350 & 60 & 130 & 100 & 64 & 133 & 94 \\
\hline 17-CNO79/PRL"S" / / IAC 227 & 60 & 118 & 85 & 62 & 130 & 72 \\
\hline 18-WG 3070/2*WEAVER & 60 & 118 & 95 & 62 & 130 & 84 \\
\hline 19-SABUF & 71 & 135 & 85 & 71 & 137 & 88 \\
\hline 20-ALD/CEP 76630//CEP 74234/PF7219/3/BUC"S"/BJY"S" & 47 & 110 & 80 & 57 & 112 & 76 \\
\hline
\end{tabular}

Ciclo 110 - 120 dias precoce; 121 - 130 médio; > 130 dias tardio. 
Avaliaram-se, em solução nutritiva e em condição de laboratório de acordo com CAMARGO E Oliveira (1981), as plântulas dos 20 genótipos mais duas cultivares-controle: BH 1146 (tolerante) e Anahuac (sensível), a fim de determinar a tolerância à toxicidade de alumínio, usando-se as doses de 0,2 , $4,6,8$ e $10 \mathrm{mg} \mathrm{L}^{-1}$ de $\mathrm{Al}^{3+}$. O delineamento experimental utilizado foi em blocos ao acaso, com duas repetições, dispostos em parcelas subdivididas: as parcelas, compostas de seis concentrações de alumínio e, as subparcelas, de genótipos de trigo. $\mathrm{Na}$ análise dos dados considerou-se a média do comprimento da raiz primária central das dez plântulas de cada genótipo, para cada repetição. Os genótipos com crescimento radicular foram considerados tolerantes, enquanto aqueles sem crescimento das raízes, sensíveis, depois de 72 horas em solução nutritiva completa sem alumínio, que se seguiu a 48 horas de crescimento nas soluções contendo seis concentrações de alumínio, conforme Camargo e Oliveira (1981).

O comportamento das cultivares em relação à ferrugem-da-folha do trigo (Puccinia triticina Erikss., ANISKSTER et al., 1997) foi avaliado em condições naturais de infecção, em planta adulta (estádios 10.1 a 10.5 da escala de Feekes-Large), utilizando a escala modificada de Cobb, empregada por SсHRAмm et al. (1974). Essa é composta pela porcentagem estimada da área foliar infectada pela doença, acrescida de uma letra simbolizando o tipo de reação: $\mathrm{S}=$ suscetível (uredossoro grande, coalescente, sem clorose); MS = moderadamente suscetível (uredossoro médio); $\mathrm{MR}=$ moderadamente resistente (uredossoro pequeno) e $\mathrm{R}$ resistente (uredossoro minúsculo rodeado de áreas necróticas).

As doenças que causam as "manchas foliares" causadas pelo complexo de fungos necrotróficos como B. sorokiniana (mancha-marrom) e $D$. tritici repentis (mancha-bronzeada), foram avaliadas com base em escala de porcentagem de área foliar infectada, segundo Metha (1978).

A avaliação da qualidade tecnológica dos genótipos foi realizada nos experimentos de Capão Bonito (sequeiro) e Ribeirão Preto (irrigado), durante o biênio 2001-2002. A produção de grãos das repetições dos experimentos (ano) foi reunida a fim de se obter quantidade suficiente de grãos para as avaliações a seguir relacionadas.

Teor de água dos grãos: determinada pelo método $n^{\circ} 44-15 A$ da AACC (1995).

Peso do hectolitro: conforme procedimento descrito na Instrução Normativa SARC $N^{\circ} 7$, de 15/ 8/2001, do Ministério da Agricultura e do
Abastecimento (BRASIL, 2001), utilizando a balança Dalle Molle.

Dureza: determinada segundo o procedimento descrito por KosmolaK (1978), que mede o tempo, em segundos, de moagem de $4 \mathrm{~g}$ de trigo utilizando o equipamento "Micro-hardness tester" da Brabender. Os graus de dureza foram definidos como: duro (D) para tempo $<32$ segundos; semiduro (SD) tempo entre 32 e 44 segundos; semimole (SM) tempo entre 45 e 62 segundos e Mole (M) tempo $\geq 63$ segundos.

Rendimento de extração de farinha (moagem): com base no método da AACC n. ${ }^{\circ}$ 26-10A (AACC, 1995), empregando-se o moinho experimental "Brabender Quadrumat Senior", em amostra de 2 kg de grãos. Os grãos tiveram seu teor de água ajustado para 15\%, 1624 horas antes da moagem. A extração de farinha representa a porcentagem de farinha obtida em relação ao total de material obtido da moagem.

Número de Queda (Falling Number): determinado pelo método . $^{\circ}$ 56-81B da AACC (AACC, 1995), em grãos triturados em moinho Perten 3100 (Perten Instruments, Huddinge, Suécia), com peneira de $0,8 \mathrm{~mm}$.

Propriedades de mistura da massa: determinadas no farinógrafo "Brabender", pelo sistema farinhaágua, de acordo com o método n. ${ }^{\circ}$ 54-21 da AACC (AACC, 1995). Misturou-se $50 \mathrm{~g}$ de farinha (na base de $14 \%$ de umidade) com água em quantidade suficiente para centralizar a curva na linha de 500 unidades farinográficas (U.F.). Essa quantidade de água, expressa como porcentagem (\%) em relação à farinha, é referida como "Absorção". O tempo de desenvolvimento da massa (TDM) é o tempo (min) necessário para alcançar a consistência máxima; estabilidade (EST) é o tempo (min) em que a curva permanece acima ou na linha de 500 U.F., índice de tolerância à mistura (ITM) é a diferença (em U.F.) medida no topo da curva, no pico, até o topo da curva 5 minutos após o pico.

Propriedades de extensão da massa: determinadas no equipamento Alveógrafo "Chopin", de acordo com o método da AACC n ${ }^{\circ}$ 54-30A (AACC, 1995). Os parâmetros básicos das curvas alveográficas estudados foram: pressão máxima $(\mathrm{P})$; abscissa média de ruptura (L); índice de configuração da curva (P/ $\mathrm{L})$; energia de deformação da massa (W) ou trabalho mecânico necessário para expandir a bolha até sua ruptura, expressa em $10^{-4}$ Joules.

Glúten úmido: determinado segundo método 137 ICC (1982), utilizando equipamento (Glutomatic) da Perten Instruments (Hudding, Suécia).

Cor: determinada em colorímetro Kent-Jones and Martin (Henry Simon Limited, 1970) 


\section{RESULTADOS E DISCUSSÃO}

Verificaram-se efeitos significativos $(\mathrm{P}<0,01)$ pela análise da variância de acordo com a tabela 2, para anos, locais e genótipos e para as interações: anos $\mathrm{x}$ genótipos, genótipos $\mathrm{x}$ locais e anos $\mathrm{x}$ genótipos $\mathrm{x}$ locais. Para anos $\mathrm{x}$ locais o efeito não foi significativo, em relação ao rendimento de grãos, considerando em conjunto os ensaios instalados na Zona tritícola B, em condições de sequeiro. O melhor desempenho nessa condição de cultivo foi obtido pelo genótipo ALD/CEP76630// CEP74234/ PF7219/3/BUC "S" /BJY "S". Destacou-se também o genótipo MARNG/BUC "S" / / BLO "S" / PSN"S" / 3/BUC/PVN "S". Vale ressaltar o efeito altamente significativo para o fator ano, os rendimentos médios de 2002 foram maiores ao de 2001. Os rendimentos obtidos em Itapeva foram superiores ao de Capão Bonito dados esses que confirmam os já obtidos por Felicio et al. (2004).

Na tabela 3, são apresentados os dados de rendimento de grãos dos experimentos semeados com irrigação por aspersão nas localidades de Paranapanema, Ribeirão Preto e Mococa e os resultados das análises de variância conjunta dos experimentos e a individual por ano. Detectaramse os efeitos significativos para locais, genótipos e para as interações anos $x$ locais e genótipos $x$ locais $(\mathrm{P}<0,01)$. A interação anos $x$ genótipos e anos $x$ locais $x$ genótipos significativas $(P<0,05)$. $O$ efeito de anos não foi significativo, provavelmente devido aos experimentos serem irrigados. Pelos resultados, evidenciou-se o potencial produtivo do genótipo MARNG/ BUC"S" / / BLO"S" / PSN"S" / / BUC/PVN "S" que, na média geral dos seis experimentos, indicou o rendimento de $5.055 \mathrm{~kg} \mathrm{ha}^{-1}$. As condições edafoclimáticas de cada local foram apresentaram resultados significativos pela interação ano x local. O resultado reforça as observações de Felicio et al. $(1998 ; 2001)$ sobre a importância das condições climáticas regionais que ocorrem a cada ano.

Os genótipos 1, 2, 3, 6, 7, 8, 11, 12, 13 e 20 foram precoces em Capão Bonito e Ribeirão Preto, com um ciclo da emergência à maturação de 110 a 120 dias; os genótipos 5 (IAC-370) e 19 foram de ciclo tardio, com mais de 130 dias para atingir a maturação completa e os demais de ciclo médio, isto é 121 a 130 dias da emergência à maturação (Tabela 1).

Em relação à altura das plantas os genótipos 4, 7, 8, 12, 13, 17 e 20 foram os mais baixos, com altura de planta variando de 80 a $85 \mathrm{~cm}$, em Capão Bonito e de 72 a 73 cm, em Ribeirão Preto. Os genótipos 1 e 16 foram os mais altos com altura de planta de $100 \mathrm{~cm}$ em Capão Bonito e variando entre 90 e $94 \mathrm{~cm}$ em Ribeirão Preto. Os demais genótipos foram considerados de porte intermediário (Tabela 1).

O comprimento médio das raízes dos genótipos estudados, medidas após 72 horas de crescimento na solução nutritiva completa que se seguiu a 48 horas de crescimento na soluçãotratamento, contendo seis diferentes concentrações de alumínio encontra-se na tabela 4 .

Considerando o comprimento das raízes nas diferentes concentrações de alumínio, pelos resultados observou-se que os genótipos CNO79/PRL "S" / /IAC 227 e RAC 646/BH 1146 foram os mais tolerantes tendo o mesmo desenvolvimento da cultivar-controle BH 1146. Os genótipos SABUF, NJ/ PAK//CHAT/3/PRL "S" / ALD "S", CHAT "S" / CEP7780//PRL "S" /BOW "S", WG3070 / 2*WEAVER e as cultivares IAC 370, IAC 289 e IAC 350 foram sensíveis ao alumínio semelhantes ao controle ANAHUAC. Ressalta-se que os demais genótipos, de acordo com a variação no crescimento das raízes nas diferentes concentrações de alumínio, foram classificados como moderadamente sensíveis ou moderadamente tolerantes.

A ferrugem-da-folha causada pelo fungo Puccinia triticina Erikss., é das doenças que ocorrem na cultura do trigo a mais disseminada no Brasil e no mundo, ocorrendo todos os anos ocasionando reduções em rendimento de grãos e perda no peso hectolitro (PH) (Picinini e Fernandes, 1995). As avaliações para a ferrugem da folha em condições de sequeiro e em condição de irrigação por aspersão são apresentadas na tabela 5 .

Os genótipos CHAT "S" /CEP7780/ / PRL "S" /BOW "S", SABUF, WG 3070/2*WEAVER e ALDAN "S" /IAS 58//IAC 60 foram imunes ao agente causal da ferrugem-da-folha no biênio em estudo em ambos os sistemas de cultivo. As ocorrências foram mais generalizadas nas condições de sequeiro, provavelmente por serem essas regiões de maior concentração de lavouras comerciais, quando comparadas às áreas de irrigação como em Ribeirão Preto com poucas áreas de cultivo do cereal. Excluise deste raciocino a região de Paranapanema com maior índice de cultivo sob irrigação no Estado de São Paulo. A incidência da doença foi maior em 2002 na zona tritícola B. O genótipo TEMU196. 74/TANORI "S" / / IAC 24 foi o mais suscetível à doença em condições de sequeiro. Genótipos com alta incidência e reações suscetíveis não são desejáveis em um sistema de cultivo intensivo, podendo acarretar altas perdas na massa seca dos grãos. 
Tabela 2. Rendimento médio de grãos e o resumo das análises estatísticas entre os genótipos de trigo avaliados em condição de sequeiro, nas localidades de Capão Bonito e Itapeva (Zona tritícola B), do Estado de São Paulo, no período de 2001/2002

\begin{tabular}{|c|c|c|c|c|c|c|c|}
\hline \multirow{2}{*}{ Genótipos } & \multicolumn{6}{|c|}{2002} & \multirow[b]{2}{*}{ Média Geral } \\
\hline & Capão Bonito & Itapeva & Média & Capão Bonito & Itapeva & Média & \\
\hline & & & - & $\mathrm{kg} \mathrm{ha}^{-1}$ & & & \\
\hline 1-BOW"S" / GEN//IAC 24 & $1823 \mathrm{~b}-\mathrm{f}$ & 2913 a & $2368 \mathrm{ab}$ & 2357 c-e & $3302 \mathrm{~b}-\mathrm{d}$ & $2830 \mathrm{c}-\mathrm{g}$ & $2599 \mathrm{~b}-\mathrm{c}$ \\
\hline 2-MARNG / BUC"S" / / BLO"S" / PSN"S" /3 / BUC / PVN"S" & $2281 a-b$ & $2600 a-c$ & $2441 \mathrm{a}$ & $2534 \mathrm{c}-\mathrm{d}$ & $3788 a-b$ & $3161 \mathrm{~b}-\mathrm{d}$ & $2801 \mathrm{a}-\mathrm{b}$ \\
\hline $3-\mathrm{F}_{3} 71 / \mathrm{TRM} / / \mathrm{CNO} 79 / 3 / \mathrm{IAC} 24$ & $1923 \mathrm{~b}-\mathrm{d}$ & $2267 \mathrm{~b}-\mathrm{g}$ & $2095 \mathrm{ad}$ & 2347 c-e & 2510 e-f & $2429 \mathrm{~g}-\mathrm{i}$ & $2258 \mathrm{~d}-\mathrm{h}$ \\
\hline 4-THB"S" / CEP 7780/ / BUC"S" & $1479 \mathrm{~d}-\mathrm{f}$ & 2496 a-d & 1988 be & 2298 c-e & $3854 a-b$ & 3076 b-e & $2532 \mathrm{~b}-\mathrm{d}$ \\
\hline 5-IAC 370 & $1972 \mathrm{~b}-\mathrm{d}$ & 1906 f-g & 1939 ce & 3434 a & $2778 \mathrm{~d}-\mathrm{f}$ & 3105 b-e & 2522 b-e \\
\hline 6-TEMU196.74/TANORI"S" / / IAC 24 & $1764 \mathrm{~b}-\mathrm{f}$ & 2437 b-e & $2100 \mathrm{ad}$ & 2264 c-e & $2448 \mathrm{f}$ & $2356 \mathrm{~h}-\mathrm{j}$ & 2228 e-h \\
\hline 7- V.82178/IAC 24 & $1562 \mathrm{~d}-\mathrm{f}$ & $2628 a-b$ & 2095 ad & $2628 \mathrm{~b}-\mathrm{d}$ & $3378 \mathrm{~b}-\mathrm{c}$ & $3003 b-f$ & $2546 \mathrm{~b}-\mathrm{d}$ \\
\hline 8-IAC 76/IAC 162 & $1538 \mathrm{~d}-\mathrm{f}$ & $2281 \mathrm{~b}-\mathrm{g}$ & 1909 ce & 2260 c-e & 2534 e-f & $2397 \mathrm{~h}-\mathrm{j}$ & 2152 g-i \\
\hline 9-NJ/PAK//CHAT/3/PRL"S" / ALD"S" & $1625 \mathrm{~d}-\mathrm{f}$ & 2003 e-g & 1814 de & 3337 a & 2593 e-f & $2965 \mathrm{~b}-\mathrm{f}$ & $2389 c-g$ \\
\hline 10-CHAT"S" /CEP 7780//PRL"S" / BOW"S" & 1830 b-e & $2073 \mathrm{~d}-\mathrm{g}$ & 1951 ce & 2923 a-c & 3059 c-e & 2991 b-f & $2471 \mathrm{c}-\mathrm{f}$ \\
\hline 11-ALDAN"S"/IAS58//IAC 60 & $1614 \mathrm{~d}-\mathrm{f}$ & 1920 f-g & 1767 de & $2479 \mathrm{c}-\mathrm{d}$ & 3045 c-f & $2762 \mathrm{~d}-\mathrm{h}$ & 2264 d-h \\
\hline 12-RAC 646/BH 1146 & $1211 \mathrm{f}$ & $2076 \mathrm{~d}-\mathrm{g}$ & $1644 \mathrm{e}$ & 1750 d-e & 2493 e-f & $2121 \mathrm{j}$ & 1882 i \\
\hline 13-SUPER X/6/R/ /IRN 471-63*5/7/IAC 24 & 1847 b-e & $2201 \mathrm{~b}-\mathrm{g}$ & 2024 be & 2100 de & $3357 \mathrm{~b}-\mathrm{d}$ & 2729 e-h & $2376 c-g$ \\
\hline 14-BAU"S" / BH 1146 & 1545 d-f & $1823 \mathrm{~g}$ & 1684 de & 2198 d-e & $2878 \mathrm{c}-\mathrm{f}$ & $2538 \mathrm{~g}-\mathrm{i}$ & 2111 g-i \\
\hline 15-IAC 289 & $1868 \mathrm{~b}-\mathrm{e}$ & $1850 \mathrm{~g}$ & 1859 de & 3413 a & 3080 c-e & $3246 b-c$ & $2553 \mathrm{~b}-\mathrm{d}$ \\
\hline 16-IAC 350 & 1652 c-f & $1809 \mathrm{~g}$ & 1731 de & $3236 a-b$ & $3451 \mathrm{a}-\mathrm{c}$ & $3344 \mathrm{~b}$ & $2537 \mathrm{~b}-\mathrm{d}$ \\
\hline 17-CNO79/PRL"S" / / IAC 227 & 1267 e-f & $2135 c-g$ & $1701 \mathrm{de}$ & 1993 d-e & $2486 \mathrm{c}-\mathrm{f}$ & $2239 \mathrm{i}-\mathrm{j}$ & 1970 h-i \\
\hline 18-WG 3070/2*WEAVER & $1208 \mathrm{f}$ & $2236 \mathrm{~b}-\mathrm{g}$ & 1722 de & 2316 c-e & $2937 c-f$ & $2626 \mathrm{f}-\mathrm{i}$ & $2174 \mathrm{f}-\mathrm{h}$ \\
\hline 19-SABUF & $2590 \mathrm{a}$ & $2166 \mathrm{~b}-\mathrm{g}$ & $2378 \mathrm{ab}$ & 2941 a-c & $3031 \mathrm{c}-\mathrm{f}$ & 2986 b-f & $2682 b-c$ \\
\hline 20-ALD/CEP 76630 / /CEP 74234/PF 219/3/BUC"S" / BJY"S" & 2246 a-c & $2340 \mathrm{~b}-\mathrm{f}$ & $2293 \mathrm{ac}$ & 3475 a & 3993 a & 3734 a & 3014 a \\
\hline Média & $1742 \mathrm{~B}$ & $2208 \mathrm{~A}$ & 1975 & 2618 B & $3050 \mathrm{~A}$ & 2832 & 2403 \\
\hline Ano & & & & & & & $450,23^{* *}$ \\
\hline Local & - & - & $67,66^{* *}$ & - & - & $58,98^{* *}$ & $124,04^{* *}$ \\
\hline Genótipo & $3,74^{* *}$ & $4,39 * *$ & $3,82^{* *}$ & $6,14^{* *}$ & $7,26^{* *}$ & $10,35^{* *}$ & $9,49 * *$ \\
\hline Ano $x$ Local & - & - & - & - & - & - & $0,13 \mathrm{~ns}$ \\
\hline Ano $x$ genótipo & - & - & - & - & - & - & $4,43^{* *}$ \\
\hline Genótipo x local & - & - & $2,88^{*}$ & - & - & $5,53^{* *}$ & $2,24^{* *}$ \\
\hline Ano $x$ Local $x$ genótipo & - & - & - & - & - & - & $2,12^{*}$ \\
\hline $\mathrm{CV} \%$ & 21,08 & 12,86 & 18,12 & 16,16 & 11,68 & 12,65 & 15,04 \\
\hline
\end{tabular}

Médias para comparação do rendimento de grãos entre cultivares dentro de local e na média geral em letras minúsculas e médias para comparação entre locais em letras maiúsculas. Médias seguidas por letras distintas diferem entre si pelo teste de Duncan a $5 \%$. 
Tabela 3. Rendimento médio de grãos e o resumo das análises estatística entre os genótipos de trigo avaliados em condição de irrigação por aspersão, nas localidades de Paranapanema (Zona C), Ribeirão Preto (Zona G) e em Mococa (Zona H) no Estado de São Paulo, de 2001/2002

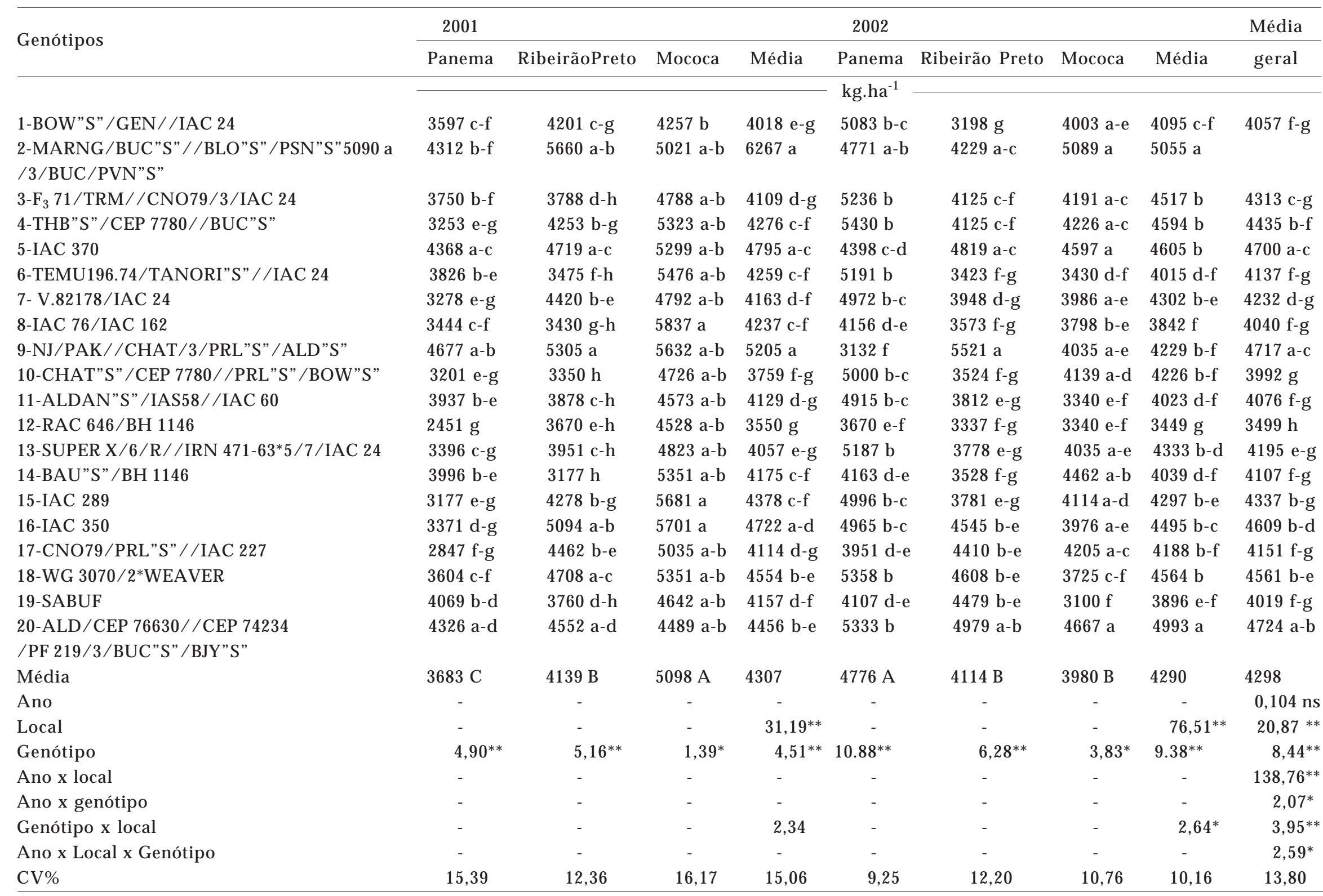

Médias para comparação da produtividade de grãos entre cultivares dentro de local e na média geral em letras minúsculas e médias para comparação entre locais em letras maiúsculas. Médias seguidas por letras distintas diferem entre si pelo teste de Duncan a $5 \%$. 
Tabela 4. Comprimento médio das raízes dos 20 genótipos de trigo, avaliados após 72 horas de crescimento em solução normal, que se seguiu a um crescimento em solução tratamento contendo seis diferentes concentrações de alumínio

\begin{tabular}{|c|c|c|c|c|c|c|c|}
\hline \multirow{2}{*}{ Genótipos } & \multicolumn{6}{|c|}{ Concentração de alumínio $\left(\mathrm{mg} \mathrm{L}^{-1}\right)$} & \multirow{2}{*}{$\begin{array}{c}\text { Nível de } \\
\text { Resistência }\end{array}$} \\
\hline & 0 & 2 & 4 & 6 & 8 & 10 & \\
\hline & & 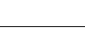 & + & + & 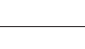 & + & \\
\hline 1-BOW"S" / GEN / / IAC 24 & 58,0 & 59,0 & 12,0 & 10,5 & 9,2 & 10,0 & MS \\
\hline 2-MARNG/BUC"S" / /BLO"S" / PSN"S" /3/BUC/PVN"S" & 58,8 & 42,6 & 25,4 & 23,4 & 11,4 & 4,0 & MS \\
\hline $3-\mathrm{F}_{3} 71 / \mathrm{TRM} / / \mathrm{CNO} 79 / 3 / \mathrm{IAC} 24$ & 66,2 & 60,6 & 47,4 & 33,0 & 33,6 & 17,4 & MT \\
\hline 4-THB"S" / CEP 7780/ / BUC"S" & 58,6 & 56,4 & 48,4 & 37,0 & 33,6 & 16,6 & MT \\
\hline 5-IAC 370 & 61,2 & 42,0 & 14,2 & 0,0 & 0,0 & 0,0 & S \\
\hline 6-TEMU196,74/TANORI"S" / / IAC 24 & 56,0 & 49,2 & 42,4 & 22,4 & 3,0 & 2,2 & MS \\
\hline $7-\mathrm{V}, 82178 / \mathrm{IAC} 24$ & 56,0 & 63,8 & 50,0 & 45,6 & 29,4 & 17,2 & MT \\
\hline 8-IAC 76/IAC 162 & 60,6 & 46,0 & 37,2 & 16,6 & 4,2 & 2,0 & MS \\
\hline 9-NJ/PAK//CHAT/3/PRL"S" / ALD"S" & 65,6 & 50,6 & 14,2 & 0,4 & 0,0 & 0,0 & S \\
\hline 10-CHAT"S" /CEP 7780//PRL"S" /BOW"S" & 67,8 & 7,6 & 0,0 & 0,0 & 0,0 & 0,0 & $\mathrm{~S}$ \\
\hline 11-ALDAN"S"/IAS58//IAC 60 & 63,4 & 61,4 & 47,8 & 37,6 & 33,4 & 20,2 & MT \\
\hline 12-RAC 646/BH 1146 & 74,6 & 70,2 & 58,4 & 60,4 & 51,2 & 28,8 & $\mathrm{~T}$ \\
\hline 13-SUPER X/6/R//IRN 471-63*5/7/IAC 24 & 64,6 & 58,0 & 36,8 & 24,6 & 14,0 & 14,0 & MS \\
\hline 14-BAU"S" / BH 1146 & 88,0 & 65,4 & 53,2 & 45,8 & 22,0 & 7,0 & MS \\
\hline 15-IAC 289 & 70,4 & 38,4 & 11,0 & 8,0 & 3,0 & 0,0 & S \\
\hline 16-IAC 350 & 68,6 & 50,4 & 15,2 & 0,0 & 0,0 & 0,0 & S \\
\hline 17-CNO79/PRL"S" / /IAC 227 & 68,0 & 63,4 & 55,2 & 47,2 & 44,6 & 40,6 & $\mathrm{~T}$ \\
\hline 18-WG 3070/2*WEAVER & 56,0 & 52,6 & 24,4 & 9,2 & 2,2 & 1,2 & $\mathrm{~S}$ \\
\hline 19-SABUF & 71,0 & 1,2 & 0,0 & 0,0 & 0,0 & 0,0 & $\mathrm{~S}$ \\
\hline 20-ALD/CEP 76630//CEP 74234//PF 7219/3 /BUC"S" / BJY"S" & 71,2 & 60,6 & 50,2 & 41,6 & 14,8 & 15,0 & MS \\
\hline BH 1146 & 75,2 & 81,6 & 66,6 & 63,8 & 50,4 & 37,8 & $\mathrm{~T}$ \\
\hline Anahuac & 73,4 & 0,0 & 0,0 & 0,0 & 0,0 & 0,0 & S \\
\hline
\end{tabular}

$\mathrm{S}=$ suscetível; $\mathrm{MS}=$ moderadamente suscetível; $\mathrm{MT}=$ moderadamente tolerante; $\mathrm{T}=$ tolerante 
Tabela 5. Reações e incidência em porcentagem de área foliar infectada por ferrugem da folha, nos genótipos de trigo avaliados em condição sequeiro em Capão Bonito e Itapeva (Zona B) e com irrigação por aspersão em Paranapanema (Zona C), Ribeirão Preto (Zona G) e em Mococa (Zona H) no Estado de São Paulo, em 2001 e 2002

\begin{tabular}{|c|c|c|c|c|c|c|c|c|c|c|}
\hline \multirow{3}{*}{ Genótipos } & \multicolumn{4}{|c|}{ Sequeiro } & \multicolumn{6}{|c|}{ Irrigado } \\
\hline & \multicolumn{2}{|c|}{ Capão Bonito } & \multicolumn{2}{|c|}{ Itapeva } & \multicolumn{2}{|c|}{ Paranapanema } & \multicolumn{2}{|c|}{ Reirão Preto } & \multicolumn{2}{|c|}{ Mococa } \\
\hline & 2001 & 2002 & 2001 & 2002 & 2001 & 2002 & 2001 & 2002 & 2001 & 2002 \\
\hline
\end{tabular}

1-BOW"S" / GEN / / IAC 24

2-MARNG/BUC"S" / BLO"S" /PSN"S"/3/BUC/PVN"S"

3-F 3 71/TRM / / CNO79/3/IAC 24

4-THB"S" / CEP 7780/ / BUC"S"

5 -IAC 370

6-TEMU196.74/TANORI"S" / / IAC 24

7- V.82178/IAC 24

8-IAC 76/IAC 162

9-NJ/PAK/ /CHAT/3/PRL"S" / ALD"S"

10-CHAT"S" / CEP 7780/ / PRL"S" / BOW"S"

11-ALDAN"S" /IAS58 / /IAC 60

12-RAC 646/BH 1146

13-SUPER X/6/R//IRN 471-63*5/7/IAC 24

14-BAU"S" / BH 1146

15-IAC 289

16-IAC 350

17-CNO79/PRL"S" / / IAC 227

18-WG 3070/2*WEAVER

19-SABUF

\begin{tabular}{cccccccccc}
\hline 0 & $10 \mathrm{MS}$ & $40 \mathrm{~S}$ & $20 \mathrm{~S}$ & 0 & $20 \mathrm{~S}$ & 0 & 0 & 0 & 0 \\
0 & 0 & $10 \mathrm{~S}$ & 0 & 0 & TMS & 0 & 0 & 0 & 0 \\
0 & $5 \mathrm{MR}$ & 0 & 0 & 0 & $10 \mathrm{~S}$ & $5 \mathrm{~S}$ & 0 & $20 \mathrm{~S}$ & 0 \\
0 & $10 \mathrm{~S}$ & 0 & 0 & 0 & $5 \mathrm{MS}$ & 0 & 0 & $5 \mathrm{MS}$ & 0 \\
0 & $30 \mathrm{~S}$ & $10 \mathrm{MR}$ & $20 \mathrm{MR}$ & $\mathrm{TS}$ & $20 \mathrm{MS}$ & $5 \mathrm{~S}$ & $\mathrm{TS}$ & $20 \mathrm{~S}$ & 0 \\
0 & $40 \mathrm{~S}$ & $30 \mathrm{~S}$ & $60 \mathrm{~S}$ & 0 & $5 \mathrm{~S}$ & 0 & 0 & $10 \mathrm{~S}$ & 0 \\
0 & 0 & $10 \mathrm{MR}$ & 0 & 0 & 0 & $0-\mathrm{TS}$ & 0 & 0 & 0 \\
0 & $40 \mathrm{~S}$ & $30 \mathrm{~S}$ & $40 \mathrm{~S}$ & 0 & $5 \mathrm{~S}$ & $0-\mathrm{TS}$ & 0 & $40 \mathrm{~S}$ & 0 \\
0 & $30 \mathrm{~S}$ & $10 \mathrm{MR}$ & $10 \mathrm{~S}$ & $5 \mathrm{~S}$ & $10 \mathrm{~S}$ & $5 \mathrm{~S}$ & 0 & $40 \mathrm{~S}$ & 0 \\
0 & 0 & 0 & 0 & 0 & 0 & 0 & 0 & 0 & 0 \\
0 & 0 & 0 & 0 & 0 & 0 & 0 & 0 & 0 & 0 \\
0 & 0 & $\mathrm{TR}$ & $5 \mathrm{~S}$ & 0 & 0 & 0 & 0 & 0 & 0 \\
0 & 0 & 0 & 0 & 0 & 0 & 0 & 0 & $20 \mathrm{~S}$ & 0 \\
0 & $10 \mathrm{MR}$ & 0 & $10 \mathrm{~S}$ & 0 & 0 & 0 & 0 & 0 & 0 \\
0 & $5 \mathrm{MR}$ & 0 & $0-20 \mathrm{~S}$ & 0 & TS & 0 & 0 & 0 & 0 \\
0 & $20 \mathrm{~S}$ & $20 \mathrm{~S}$ & $0-10 \mathrm{~S}$ & 0 & $20 \mathrm{MS}$ & 0 & 0 & 0 & 0 \\
0 & $40 \mathrm{~S}$ & 0 & $40 \mathrm{~S}$ & 0 & $50 \mathrm{~S}$ & 0 & 0 & $20 \mathrm{~S}$ & 0 \\
0 & 0 & 0 & 0 & 0 & 0 & 0 & 0 & 0 & 0 \\
0 & 0 & 0 & 0 & 0 & 0 & 0 & 0 & 0 & 0 \\
0 & 0 & $10 \mathrm{MS}$ & 0 & 0 & $20 \mathrm{~S}$ & $5 \mathrm{~S}$ & 0 & 0 & 0 \\
\hline
\end{tabular}

20-ALD/CEP 76630 / /CEP74234/PF219/3/BUC"S" / BJY"S"

$\mathrm{S}=$ Suscetível; $\mathrm{R}=$ resistente; $\mathrm{MS}=$ moderadamente suscetível $; \mathrm{MR}=$ moderadamente resistente; $\mathrm{t}=$ traço. 
As manchas foliares causadas por $B$. sorokiniana e $D$. tritici repentis, estavam com níveis de infecção mais elevados nos experimentos semeados em condições de sequeiro. Em condições de irrigação por aspersão a incidência das manchas foliares foi menor (Tabela 6). Segundo Felicio et al. (2004), as precipitações pluviais que ocorrem com intensidade, na época do florescimento da cultura do trigo, na Região de Sudoeste do Estado de São Paulo (Capão Bonito), é fator importante para o aparecimento de doenças causadas por fungos necrotróficos, pois sendo doenças policíclicas, de acordo com FernANDES E FERNANDEZ (1991), podem completar vários ciclos em uma mesma lavoura, uma vez instalada, afetando conseqüentemente o rendimento de grãos. Os genótipos estavam com diferentes índices de incidência da doença. No genótipo SABUF observou-se a menor incidência nos diferentes meios de cultivos.

As características tecnológicas dos grãos dos genótipos em estudo foram avaliadas em 2001/ 2002 com base nos experimentos de Capão Bonito (Tabelas 7 e 8 ), para as condições de sequeiro e Ribeirão Preto para o ambiente com irrigação por aspersão (Tabelas 9 e 10).

Pelos resultados verifica-se variação entre os anos e locais para o PH (peso hectolitro). Para a extração de farinha, os resultados estão de acordo com o padrão para moinhos experimentais acima de $70 \%$ para os genótipos de grãos duro ou semiduro e abaixo desse valor para os considerados brandos, resultados já observados por Felicio et al. (1998 e 2001).

Na comercialização, o trigo é classificado com base em características que determinam seu uso na elaboração de diversos produtos. Assim podemos classificar para panificação pela dureza de seus grãos os genótipos: BOW "S" /GEN//IAC 24; MARNG/BUC "S" / / BLO “S" /PSN "S" /3/BUC/PVN "S"; WG 3070/ 2*WEAVER e SABUF como duros e como trigos brandos utilizados na fabricação de bolachas os genótipos: RAC 646/BH 1146, BAU "S" /BH 1146, CNO70/PRL "S" / /IAC 227 e ALD/CEP76630// CEP74234/PF219/3/ BUC "S" /BJY "S". Os demais se classificam como trigos semiduros utilizados principalmente na panificação dependendo dos resultados obtidos nas análises farinográficas e alveográficas.

As farinhas provenientes dos grãos de Ribeirão Preto foram mais claras que as de Capão Bonito. Entre elas destacam-se os genótipos 10 e 13, embora os genótipos 12, 17 e 18 em 2001, e o 14 em 2002, também estavam bastante claros.

Pelos resultados da análise do número de queda (NQ), constatou-se que em Capão Bonito não ocorreu o processo germinativo dos grãos na espiga, entretanto, em Ribeirão Preto a atividade da alfaamilase dos grãos foi detectada nos genótipos 8 e 12 em 2001, e nos genótipos 4, 7, 8, 12 e 15 em 2002 degradando o amido existente no endosperma e, como conseqüência, contribuindo para os baixos valores de W (força do glúten).

Segundo PeÑa et al. (1998) a indústria moageira requer cultivares de trigo com distintos tipos de qualidade que respondam as suas demanda nos diferentes produtos a serem elaborados pelos diversos tipos de farinha. Os parâmetros farinográficos e alveográficos avaliados conjuntamente nas tabelas 8 (Capão Bonito) e 10 (Ribeirão Preto), permitem tipificar a farinha proveniente dos diferentes genótipos de trigo quanto ao seu uso industrial mais viável.

O genótipo TEMU196.74/TANORI "S" / /IAC 24 se classifica como trigo "melhorador", segundo a Instrução Normativa n. ${ }^{\circ} 7$ do Ministério da Agricultura e Abastecimento (BRASIL, 2001). Caracteriza trigos com a força do glúten acima de 300 $\left(\mathrm{x} 10^{-4} \mathrm{~J}\right)$ como "melhorador", "P" (tenacidade da massa) $>80 \mathrm{~mm}$ e "L" (extensibilidade da massa) entre 50 e $60 \mathrm{~mm}$, portanto, pouco extensivo e com estabilidade da massa superior a 10 minutos.

Um segundo grupo classificado como trigo tipo "Pão", de glúten forte a médio representado pelos tratamentos 2, 3, 5, 9, 11, 1314 e 15 são utilizados principalmente, na fabricação de pães. No terceiro grupo está o trigo indesejável composto pelos genótipos 1, 4, 7, 8, 10,12,16, 17, 18, 19 e 20 possuem "L" curto (pouco extensivo) produzem massa de extensibilidade muito limitada, de pouca tolerância e deficiente capacidade de expansão durante o processo de fermentação. Seu uso é limitado, podendo ser utilizado em alguns produtos de confeitaria ou complemento de farinha forte. O ultimo grupo não deve ser alocado na classe de trigo "brando" pois os trigos dessa classe têm "L" longo >120 mm e "W" entre 180 - 220 ( $\left.\times 10^{-4} \mathrm{~J}\right)$ de força do glúten.

O teor de glúten é um parâmetro utilizado na determinação da qualidade e quantidade das proteínas insolúveis do trigo. Pode ser expresso tanto em termos de glúten úmido ou glúten seco, portanto, quanto mais alta é a porcentagem de glúten extraído da farinha, mais elevado é o número de partículas de proteína por unidade de volume de massa.

Em Capão Bonito (sequeiro) a porcentagem de glúten úmido foi ligeiramente superior em relação à de Ribeirão Preto. Nessa última localidade, a irrigação foi utilizada para reduzir o efeito do estresse hídrico regional e como conseqüência os rendimentos de grãos obtidos foram superiores aos obtidos na Região Sudoeste em condições de sequeiro. O teor de glúten foi mais expressivo nos genótipo 5 e 11 em 2002 em Capão Bonito, enquanto em Ribeirão Preto nos genótipos 3,14 e 19, em 2001, e nos genótipos 3,11 e 19n em 2002, verificaram-se as maiores porcentagens de glúten úmido. 
Tabela 6. Incidência de manchas foliares, causadas por B. sorokiniana e D. tritici repentis em porcentagem de área foliar infectada, nos genótipos de trigo avaliados em condição sequeiro em Capão Bonito e Itapeva (Zona B) e com irrigação por aspersão em Paranapanema (Zona C ), Ribeirão Preto (Zona G) e em Mococa (Zona H) no Estado de São Paulo, em 2001 e 2002

\begin{tabular}{|c|c|c|c|c|c|c|c|c|c|c|}
\hline \multirow{3}{*}{ Genótipos } & \multicolumn{4}{|c|}{ Sequeiro } & \multicolumn{4}{|c|}{ Irrigado } & \multirow{2}{*}{\multicolumn{2}{|c|}{ Mococa }} \\
\hline & Cap & nito & & & Paran & ema & Ribei & Preto & & \\
\hline & 2001 & 2002 & 2001 & 2002 & 2001 & 2002 & 2001 & 2002 & 2001 & 2002 \\
\hline
\end{tabular}

\section{1-BOW"S" / GEN/ / IAC 24}

2-MARNG/BUC"S"/ /BLO"S" /PSN"S"/

3/BUC/PVN"S"

3-F 3 71/TRM/ /CNO79/3/IAC 24

4-THB"S" / CEP 7780 / / BUC"S"

5-IAC 370

6-TEMU196.74/TANORI"S" / / IAC 24

7- V.82178/IAC 24

8-IAC 76/IAC 162

9-NJ/PAK//CHAT/3/PRL"S" / ALD"S"

10-CHAT"S" / CEP 7780/ / PRL"S" / BOW"S"

11-ALDAN"S" /IAS58 / / IAC 60

12-RAC 646/BH 1146

13-SUPER X/6/R/ / IRN 471-63*5/7 /IAC 24

14-BAU"S" / BH 1146

15-IAC 289

16-IAC 350

17-CNO79/PRL"S" / / IAC 227

18-WG 3070/2*WEAVER

19-SABUF

20-ALD/CEP 76630/ /CEP74234/PF219

/3/BUC"S" / BJY"S"

\begin{tabular}{|c|c|c|c|c|c|c|c|c|c|}
\hline 30 & 30 & 40 & 40 & 20 & 20 & 5 & 10 & 20 & $<5$ \\
\hline 30 & 30 & 40 & 30 & 10 & 20 & 5 & 5 & 20 & $<5$ \\
\hline 30 & 30 & 40 & 40 & 10 & 20 & 5 & 5 & 20 & $<5$ \\
\hline 60 & 50 & 60 & 40 & 20 & 20 & 5 & 5 & 20 & $<5$ \\
\hline 30 & 30 & 60 & 40 & 10 & 20 & 5 & 5 & 20 & $<5$ \\
\hline 40 & 30 & 50 & 30 & 20 & 20 & 5 & 5 & 20 & $<5$ \\
\hline 40 & 40 & 50 & 30 & 20 & 20 & 5 & 10 & 20 & $<5$ \\
\hline 40 & 40 & 50 & 50 & 20 & 20 & 5 & 5 & 20 & $<5$ \\
\hline 30 & 30 & 60 & 30 & 10 & 20 & 5 & 5 & 20 & $<5$ \\
\hline 30 & 30 & 60 & 30 & 10 & 20 & 5 & 5 & 20 & $<5$ \\
\hline 30 & 20 & 40 & 30 & 10 & 20 & 5 & 5 & 20 & $<5$ \\
\hline 30 & 30 & 60 & 30 & 20 & 20 & 5 & 5 & 20 & $<5$ \\
\hline 30 & 50 & 80 & 30 & 20 & 20 & 5 & 5 & 20 & $<5$ \\
\hline 50 & 40 & 50 & 30 & 20 & 20 & 5 & 10 & 20 & $<5$ \\
\hline 30 & 30 & 50 & 30 & 20 & 20 & 5 & 5 & 20 & $<5$ \\
\hline 40 & 30 & 50 & 30 & 20 & 20 & 5 & 5 & 20 & $<5$ \\
\hline 60 & 40 & 80 & 40 & 20 & 20 & 5 & 5 & 20 & $<5$ \\
\hline 40 & 30 & 60 & 30 & 20 & 20 & 5 & 5 & 20 & $<5$ \\
\hline 20 & 30 & 30 & 20 & 10 & 10 & 5 & 5 & 10 & $<5$ \\
\hline 40 & 30 & 40 & 30 & 20 & 20 & 5 & 5 & 20 & $<5$ \\
\hline
\end{tabular}


Tabela 7. Peso Hectolitro (PH), extração experimental de farinha (Ext), dureza do grão (DZ), cor da farinha (CRF), número de queda (NQ) em segundos (s), dos genótipos de trigo avaliados em condição de sequeiro, na localidade de Capão Bonito Zona tritícola B no Estado de São Paulo, em 2001/2002

\begin{tabular}{|c|c|c|c|c|c|c|c|c|c|c|}
\hline \multirow{2}{*}{ Genótipos } & \multicolumn{5}{|c|}{2001} & \multicolumn{5}{|c|}{2002} \\
\hline & $\mathrm{PH}$ & Ext & $\mathrm{DZ}$ & CRF & NQ & $\mathrm{PH}$ & Ext & $\mathrm{DZ}$ & CRF & NQ \\
\hline & $\mathrm{kg} / \mathrm{hl}$ & $\%$ & $\mathrm{~s}$ & pontos & $\mathrm{s}$ & $\mathrm{kg} / \mathrm{hl}$ & $\%$ & $\mathrm{~s}$ & pontos & $\mathrm{s}$ \\
\hline 1-BOW"S" / GEN / / IAC 24 & 71.2 & 68.9 & 31 & 4.02 & 432 & 78.2 & 73.8 & 24 & 3.50 & 392 \\
\hline 2-MARNG / BUC"S" / / BLO"S" / PSN"S" /3/BUC/PVN"S" & 79.7 & 72.2 & 26 & 2.87 & 494 & 84.3 & 75.6 & 23 & 3.27 & 416 \\
\hline $3-\mathrm{F}_{3} 71 / \mathrm{TRM} / / \mathrm{CNO} 79 / 3 / \mathrm{IAC} 24$ & 79.5 & 65.9 & 36 & 2.92 & 557 & 81.7 & 71.0 & 29 & 4.65 & 473 \\
\hline 4-THB"S" / CEP 7780/ / BUC"S" & 74.3 & 69.5 & 29 & 5.50 & 475 & 81.4 & 73.3 & 25 & 2.75 & 414 \\
\hline 5-IAC 370 & 77.4 & 69.9 & 26 & 3.77 & 506 & 80.4 & 74.4 & 26 & 2.45 & 439 \\
\hline 6-TEMU196.74/TANORI"S" / / IAC 24 & 75.9 & 73.8 & 38 & 5.45 & 444 & 82.0 & 75.2 & 26 & 3.87 & 448 \\
\hline 7- V.82178/IAC 24 & 69.2 & 69.9 & 34 & 8.20 & 431 & 76.8 & 70.3 & 26 & 3.25 & 338 \\
\hline 8-IAC 76/IAC 162 & 75.2 & 71.3 & 32 & 6.15 & 437 & 79.9 & 76.5 & 27 & 5.05 & 337 \\
\hline 9-NJ/PAK/ /CHAT/3/PRL"S"/ALD"S" & 72.7 & 72.4 & 32 & 7.00 & 505 & 80.8 & 74.7 & 25 & 3.25 & 423 \\
\hline 10-CHAT"S" /CEP 7780 / / PRL"S" / BOW"S" & 79.3 & 71.8 & 44 & 2.92 & 476 & 83.6 & 71.4 & 46 & 1.55 & 401 \\
\hline 11-ALDAN"S" /IAS58 / /IAC 60 & 77.3 & 72.0 & 31 & 3.07 & 508 & 81.7 & 71.7 & 29 & 2.95 & 393 \\
\hline 12-RAC 646/BH 1146 & 75.5 & 64.5 & 35 & 3.05 & 359 & 81.3 & 65.5 & 87 & 2.55 & 242 \\
\hline 13-SUPER X/6/R//IRN 471-63*5/7/IAC 24 & 76.8 & 73.7 & 78 & 3.32 & 442 & 80.7 & 74.2 & 23 & 3.70 & 374 \\
\hline 14-BAU”S" / BH 1146 & 78.4 & 65.2 & 24 & 3.05 & 423 & 82.2 & 68.5 & 100 & 3.65 & 290 \\
\hline 15-IAC 289 & 72.5 & 69.0 & 43 & 4.55 & 353 & 79.7 & 73.0 & 26 & 2.50 & 294 \\
\hline 16-IAC 350 & 76.1 & 72.0 & 32 & 3.50 & 376 & 82.9 & 75.7 & 25 & 2.82 & 315 \\
\hline 17-CNO79/PRL"S" / / IAC 227 & 78.1 & 63.8 & 77 & 2.40 & 363 & 81.1 & 67.2 & 127 & 2.80 & 256 \\
\hline 18-WG 3070/2*WEAVER & 79.0 & 74.5 & 20 & 3.65 & 509 & 81.4 & 74.1 & 23 & 3.55 & 437 \\
\hline 19-SABUF & 78.6 & 74.9 & 26 & 4.35 & 590 & 80.3 & 76.8 & 23 & 3.05 & 534 \\
\hline 20-ALD/CEP 76630//CEP 74234/PF 219/3/BUC"S" /BJY"S" & 77.7 & 69.6 & 89 & 5.77 & 387 & 81.8 & 72.7 & 54 & 4.10 & 341 \\
\hline
\end{tabular}


Tabela 8. Dados da farinografia (tempo de desenvolvimento da massa - TDM e estabilidade - EST) e da alveografia $\left(\mathrm{P}=\right.$ tenacidade, $\mathrm{L}=$ extensibilidade e $\mathrm{W}\left(10^{-4} \mathrm{~J}\right)$ força do glúten e do glúten úmido (GU) dos genótipos de trigo avaliados em condição de sequeiro, na localidade de Capão Bonito (Zona tritícola B) no Estado de São Paulo, em 2001/2002

\begin{tabular}{|c|c|c|c|c|c|c|c|c|c|c|c|c|}
\hline \multirow{2}{*}{ Genótipos } & \multicolumn{6}{|c|}{2001} & \multicolumn{6}{|c|}{2002} \\
\hline & TDM & EST & $\mathrm{P}$ & $\mathrm{L}$ & \multirow{2}{*}{$\frac{\mathrm{W}}{10^{-4} \mathrm{~J}}$} & \multirow{2}{*}{$\begin{array}{c}\mathrm{GU} \\
\%\end{array}$} & TDM & EST & $\mathrm{P}$ & $\mathrm{L}$ & \multirow{2}{*}{$\frac{\mathrm{W}}{10^{-4} \mathrm{~J}}$} & \multirow{2}{*}{$\begin{array}{c}\text { GU } \\
\%\end{array}$} \\
\hline & 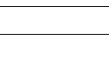 & 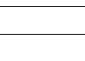 & 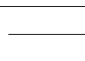 & 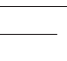 & & & +2 & 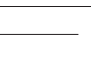 & - & 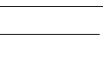 & & \\
\hline 1-BOW"S" / GEN//IAC 24 & 5,5 & 8,5 & 130 & 54 & 272 & 25,6 & 6,1 & 11,3 & 163 & 51 & 348 & 23,5 \\
\hline $\begin{array}{l}\text { 2-MARNG /BUC"S" / /BLO"S" / PSN"S" } \\
\text { /3/BUC/PVN"S" }\end{array}$ & 4,9 & 5,7 & 115 & 60 & 236 & 25,9 & 5,3 & 6,2 & 136 & 72 & 348 & 27,6 \\
\hline $3-\mathrm{F}_{3} 71 / \mathrm{TRM} / / \mathrm{CNO} 79 / 3 / \mathrm{IAC} 24$ & 6,5 & 7,3 & 123 & 63 & 295 & 26,9 & 6,3 & 10,4 & 161 & 64 & 408 & 29,1 \\
\hline 4-THB"S" / CEP 7780 / / BUC"S" & 5,0 & 7,2 & 133 & 57 & 245 & 25,0 & 5,1 & 5,0 & 148 & 66 & 304 & 26,7 \\
\hline 5 -IAC 370 & 8,0 & 13,2 & 137 & 54 & 295 & 25,5 & 6,1 & 12,4 & 116 & 67 & 302 & 33,3 \\
\hline 6-TEMU196,74/TANORI"S" / /IAC 24 & 7,0 & 8,7 & 176 & 53 & 452 & 26,4 & 8,2 & 18,7 & 200 & 67 & 591 & 23,2 \\
\hline $7-\mathrm{V}, 82178 / \mathrm{IAC} 24$ & 5,3 & 5,9 & 143 & 55 & 298 & 28,4 & 4,2 & 6,5 & 129 & 59 & 289 & 27,2 \\
\hline 8-IAC 76/IAC 162 & 4,7 & 4,7 & 125 & 54 & 245 & 27,1 & 5,2 & 6,1 & 121 & 58 & 250 & 27,7 \\
\hline 9-NJ/PAK/ /CHAT/3/PRL"S" / ALD"S" & 6,9 & 8,3 & 160 & 44 & 276 & 20,4 & 5,2 & 11,5 & 128 & 54 & 285 & 20,0 \\
\hline 10-CHAT"S" /CEP 7780/ /PRL"S" /BOW"S" & 4,9 & 5,9 & 98 & 56 & 176 & 25,2 & 5,5 & 7,2 & 102 & 69 & 231 & 26,9 \\
\hline 11-ALDAN"S"/IAS58 / /IAC 60 & 5,5 & 8,7 & 110 & 49 & 210 & 28,6 & 6,5 & 9,9 & 116 & 75 & 326 & 32,4 \\
\hline 12-RAC 646/BH 1146 & 5,0 & 7,0 & 79 & 78 & 182 & 27,5 & 4,8 & 6,4 & 66 & 104 & 190 & 28,8 \\
\hline 13-SUPER X/6/R/ /IRN 471-63*5/7/IAC 24 & 6,1 & 6,9 & 130 & 49 & 241 & 26,4 & 6,2 & 8,0 & 139 & 63 & 338 & 26,4 \\
\hline 14-BAU"S" / BH 1146 & 6,7 & 6,5 & 100 & 67 & 234 & 28,0 & 6,6 & 8,7 & 95 & 94 & 286 & 29,1 \\
\hline 15-IAC 289 & 6,1 & 6,8 & 120 & 45 & 213 & 22,1 & 6,1 & 8,8 & 111 & 65 & 257 & 23,7 \\
\hline 16-IAC 350 & 5,0 & 6,5 & 115 & 42 & 196 & 26,3 & 5,2 & 7,8 & 113 & 54 & 235 & 28,5 \\
\hline 17-CNO79/PRL"S" / /IAC 227 & 4,9 & 6,5 & 69 & 61 & 129 & 25,7 & 4,0 & 5,7 & 95 & 67 & 197 & 28,0 \\
\hline 18-WG 3070/2*WEAVER & 4,4 & 4,7 & 119 & 35 & 164 & 28,3 & 5,0 & 5,0 & 111 & 64 & 242 & 29,0 \\
\hline 19-SABUF & 3,8 & 4,6 & 125 & 40 & 188 & 26,1 & 4,5 & 4,3 & 112 & 72 & 252 & 27,3 \\
\hline $\begin{array}{l}\text { 20-ALD/CEP 76630//CEP 74234/ } \\
\text { PF 219/3/BUC"S" / BJY"S" }\end{array}$ & 4,5 & 6,3 & 118 & 44 & 197 & 26,4 & 4,5 & 6,1 & 97 & 85 & 241 & 27,4 \\
\hline
\end{tabular}


Tabela 9. Peso Hectolitro (PH), extração experimental de farinha (Ext), dureza do grão (DZ), cor da farinha (CRF), número de queda (NQ) em segundos (s), dos genótipos de trigo avaliados em condição de irrigação por aspersão na localidade de Ribeirão Preto (Zona tritícola G), no Estado de São Paulo, em 2001/2002

\begin{tabular}{|c|c|c|c|c|c|c|c|c|c|c|}
\hline \multirow{2}{*}{ Genótipos } & \multicolumn{5}{|c|}{2001} & \multicolumn{5}{|c|}{2002} \\
\hline & $\mathrm{PH}$ & Ext & DZ & CRF & NQ & $\mathrm{PH}$ & Ext & DZ & CRF & NQ \\
\hline & $\mathrm{kg} / \mathrm{hl}$ & $\%$ & $\mathrm{~s}$ & pontos & $\mathrm{s}$ & $\mathrm{kg} / \mathrm{hl}$ & $\%$ & $\mathrm{~s}$ & pontos & $\mathrm{s}$ \\
\hline 1-BOW"S" / GEN//IAC 24 & 75.9 & 72.9 & 25 & 2.15 & 460 & 70.8 & 73.2 & 22 & 3.85 & 308 \\
\hline 2-MARNG/BUC"S" / / BLO"S" / PSN"S" /3/BUC / PVN"S" & 79.9 & 72.9 & 25 & 1.72 & 414 & 80.4 & 74.1 & 19 & 2.22 & 385 \\
\hline $3-\mathrm{F}_{3} 71 / \mathrm{TRM} / / \mathrm{CNO} 79 / 3 / \mathrm{IAC} 24$ & 78.4 & 66.2 & 31 & 2.30 & 385 & 77.4 & 68.6 & 27 & 2.50 & 323 \\
\hline 4-THB"S" / CEP 7780/ / BUC"S" & 74.3 & 70.5 & 27 & 2.55 & 201 & 75.2 & 71.3 & 21 & 2.80 & 171 \\
\hline 5-IAC 370 & 78.6 & 70.4 & 26 & 1.80 & 334 & 79.5 & 73.6 & 22 & 2.00 & 273 \\
\hline 6-TEMU196.74/TANORI"S" / /IAC 24 & 73.6 & 69.5 & 30 & 2.15 & 207 & 75.7 & 72.4 & 22 & 2.32 & 213 \\
\hline 7- V.82178/IAC 24 & 72.7 & 70.6 & 36 & 3.05 & 255 & 72.5 & 69.1 & 24 & 2.40 & 162 \\
\hline 8-IAC 76/IAC 162 & 75.4 & 71.7 & 26 & 3.47 & 139 & 76.8 & 74.6 & 21 & 3.20 & 176 \\
\hline 9-NJ/PAK//CHAT/3/PRL"S" / ALD"S" & 78.3 & 71.1 & 26 & 2.32 & 302 & 82.0 & 73.0 & 21 & 2.10 & 305 \\
\hline 10-CHAT"S" /CEP 7780//PRL"S" / BOW"S" & 77.9 & 65.7 & 46 & 1.07 & 423 & 79.0 & 70.8 & 28 & 1.17 & 271 \\
\hline 11-ALDAN"S" /IAS58//IAC 60 & 76.8 & 70.7 & 32 & 2.05 & 426 & 77.3 & 69.9 & 25 & 2.27 & 271 \\
\hline 12-RAC 646/BH 1146 & 75.4 & 65.1 & 500 & 1.20 & 181 & 75.7 & 67.7 & 55 & 1.97 & 152 \\
\hline 13-SUPER X/6/R//IRN 471-63*5/7/IAC 24 & 78.4 & 71.6 & 22 & 1.12 & 250 & 78.8 & 71.9 & 20 & 1.32 & 333 \\
\hline 14-BAU"S" / BH 1146 & 78.6 & 61.5 & 59 & 1.90 & 301 & 79.7 & 64.4 & 63 & 1.40 & 270 \\
\hline 15-IAC 289 & 76.1 & 70.1 & 32 & 2.17 & 247 & 74.3 & 69.9 & 27 & 1.65 & 114 \\
\hline 16-IAC 350 & 75.0 & 70.7 & 29 & 2.12 & 289 & 77.7 & 72.5 & 22 & 1.97 & 201 \\
\hline 17-CNO79/PRL"S" / / IAC 227 & 77.3 & 58.4 & 500 & 1.42 & 355 & 78.2 & 63.5 & 73 & 1.55 & 263 \\
\hline 18-WG 3070/2*WEAVER & 76.8 & 71.4 & 24 & 1.32 & 474 & 79.5 & 73.8 & 21 & 1.65 & 334 \\
\hline 19-SABUF & 75.5 & 72.1 & 25 & 2.90 & 457 & 76.8 & 73.3 & 21 & 2.85 & 316 \\
\hline 20-ALD/CEP 76630//CEP 74234/PF 219/3/BUC"S" /BJY"S" & 76.3 & 65.0 & 66 & 2.95 & 403 & 78.4 & 69.1 & 44 & 2.50 & 277 \\
\hline
\end{tabular}


Tabela 10. Dados da farinografia (tempo de desenvolvimento da massa - TDM e estabilidade - EST) e da alveografia $\left(P=\right.$ tenacidade, $\mathrm{L}=$ extensibilidade) e $\mathrm{W}\left(10^{-4} \mathrm{~J}\right)$ força do glúten e glúten úmido (GU) dos genótipos de trigo avaliados em condição de irrigação, na localidade de Ribeirão Preto Zona G, no Estado de São Paulo, em $2001 / 2002$

\begin{tabular}{|c|c|c|c|c|c|c|c|c|c|c|c|c|}
\hline \multirow{2}{*}{ Genótipos } & \multicolumn{6}{|c|}{2001} & \multicolumn{6}{|c|}{2002} \\
\hline & TDM & EST & $\mathrm{P}$ & $\mathrm{L}$ & $\mathrm{W}$ & GU & TDM & EST & $\mathrm{P}$ & $\mathrm{L}$ & W & GU \\
\hline & \multicolumn{4}{|c|}{$\underline{\min }$} & $10^{-4} \mathrm{~J}$ & $\%$ & \multicolumn{4}{|c|}{$\min \longrightarrow$} & $10^{-4} \mathrm{~J}$ & $\%$ \\
\hline 1-BOW"S" / GEN / / IAC 24 & 6,0 & 9,6 & 116 & 43 & 225 & 23,0 & 9,3 & 12,3 & 66 & 121 & 264 & 24,2 \\
\hline 2-MARNG/BUC"S" / /BLO"S" / PSN"S"/3/BUC/PVN"S" & 7,0 & 8,1 & 95 & 80 & 259 & 28,0 & 6,0 & 10,0 & 69 & 106 & 208 & 26,3 \\
\hline $3-\mathrm{F}_{3} 71 / \mathrm{TRM} / / \mathrm{CNO} 79 / 3 / \mathrm{IAC} 24$ & 7,3 & 9,0 & 99 & 93 & 331 & 31,5 & 7,2 & 12,1 & 81 & 102 & 288 & 30,6 \\
\hline 4-THB"S" / CEP 7780 / / BUC"S" & 2,7 & 2,0 & 42 & 56 & 67 & 23,6 & 3,7 & 2,1 & 58 & 94 & 113 & 26,7 \\
\hline 5-IAC 370 & 5,3 & 10,3 & 109 & 54 & 252 & 22,3 & 7,0 & 10,9 & 86 & 71 & 235 & 16,7 \\
\hline 6-TEMU196,74/TANORI"S" / / IAC 24 & 7,1 & 10,6 & 134 & 54 & 347 & 23,0 & 6,1 & 9,0 & 99 & 64 & 280 & 21,5 \\
\hline 7- V,82178/IAC 24 & 5,5 & 5,7 & 92 & 54 & 182 & 24,5 & 3,3 & 5,1 & 59 & 101 & 159 & 27,2 \\
\hline 8-IAC 76/IAC 162 & 3,8 & 3,6 & 66 & 70 & 143 & 29,8 & 4,7 & 5,5 & 60 & 112 & 191 & 28,6 \\
\hline 9-NJ/PAK/ /CHAT/3/PRL"S" / ALD"S" & 5,7 & 9,3 & 118 & 48 & 247 & 22,0 & 6,6 & 17,4 & 109 & 72 & 323 & 21,9 \\
\hline 10-CHAT"S" /CEP 7780//PRL"S" / BOW"S" & 6,5 & 7,9 & 81 & 69 & 194 & 22,8 & 5,7 & 7,6 & 57 & 105 & 180 & 28,9 \\
\hline 11-ALDAN"S" /IAS58 / /IAC 60 & 5,5 & 6,5 & 87 & 71 & 217 & 27,4 & 5,9 & 9,9 & 76 & 79 & 229 & 33,5 \\
\hline 12-RAC 646/BH 1146 & 6,0 & 6,9 & 55 & 77 & 144 & 24,2 & 4,5 & 8,4 & 39 & 111 & 140 & 25,1 \\
\hline 13-SUPER X/6/R/ /IRN 471-63*5/7/IAC 24 & 4,0 & 6,9 & 70 & 89 & 199 & 25,7 & 5,2 & 9,3 & 77 & 96 & 239 & 26,0 \\
\hline 14-BAU"S" / BH 1146 & 6,8 & 7,1 & 80 & 83 & 235 & 31,7 & 6,8 & 12,3 & 69 & 103 & 262 & 27,9 \\
\hline 15-IAC 289 & 5,3 & 6,0 & 79 & 75 & 185 & 27,2 & 6,0 & 6,9 & 53 & 108 & 159 & 23,5 \\
\hline 16-IAC 350 & 5,5 & 5,3 & 68 & 77 & 152 & 25,8 & 4,4 & 6,7 & 60 & 93 & 170 & 25,4 \\
\hline 17-CNO79/PRL"S" / / IAC 227 & 4,6 & 6,0 & 72 & 80 & 188 & 25,5 & 4,2 & 8,5 & 70 & 98 & 214 & 21,3 \\
\hline 18-WG 3070/2*WEAVER & 5,0 & 4,4 & 77 & 65 & 162 & 26,6 & 5,4 & 7,9 & 71 & 120 & 239 & 28,7 \\
\hline 19-SABUF & 3,7 & 3,0 & 76 & 59 & 133 & 30,5 & 4,5 & 5,0 & 69 & 91 & 160 & 30,6 \\
\hline 20-ALD/CEP 76630//CEP 74234/PF 219/3/BUC"S" / BJY"S" & 4,5 & 4,0 & 76 & 70 & 157 & 24,7 & 4,0 & 6,7 & 73 & 75 & 169 & 25,8 \\
\hline
\end{tabular}


Na soma dos parâmetros avaliados, a qualidade tecnológica das amostras de farinhas procedentes de Capão Bonito, Região Sudeste do Estado São Paulo, foram superiores às obtidas em Ribeirão Preto. Segundo Mandarino (1993) e PeÑa et al. (1998) fatores climáticos como altas temperaturas, durante o período compreendido entre a floração e a maturação dos grãos, podem favorecer o aumento no teor protéico; e quando ocorre a diminuição no rendimento de grãos geralmente há aumento no conteúdo da proteína dos grãos.

\section{CONCLUSÕES}

1. O genótipo ALD/CEP76630//CEP74234/ PF7219/3/BUC "S"/BJY "S" foi o de melhor desempenho na condição de cultura de sequeiro. Destacou-se o genótipo MARNG/BUC "S" / / BLO "S"/PSN "S"/3/BUC/PVN "S" (IAC 375) no ambiente com irrigação por aspersão.

2. Os genótipos CNO79/PRL "S" / /IAC 227 e RAC 646/BH 1146 foram os mais tolerantes nas concentrações de alumínio tóxico consideradas com o mesmo desempenho da cultivar-controle BH 1146.

3. CHAT"S" / CEP7780 / / PRL "S" / BOW "S", SABUF, WG 3070/2*WEAVER e ALDAN"S" /IAS 58/ /IAC 60 foram imunes ao agente causal da ferrugem da folha no biênio em estudo em ambos sistemas de cultivo.

4. O genótipo TEMU196.74/TANORI"S" / / IAC 24 classifica-se como trigo "melhorador", com força do glúten acima de $300\left(\times 10^{-4} \mathrm{~J}\right)$, " $\mathrm{P}$ " (tenacidade da massa) > $80 \mathrm{~mm}$ e "L" (extensibilidade da massa) entre 50 a $60 \mathrm{~mm}$, portanto, pouco extensivo e estabilidade da massa superior a 10 minutos.

5. A qualidade tecnológica das farinhas procedentes de Capão Bonito, Região Sudoeste do Estado São Paulo, foi superior à obtida em Ribeirão Preto, Região Central do Estado de São Paulo.

\section{REFERÊNCIAS}

AACC. AMERICAN ASSOCIATION OF CEREAL CHEMISTS. Approved methods of AACC. 9. ed. St. Paul, 1995.

BRASIL. Instrução Normativa N. ${ }^{\circ}$ 7, de 15/8/01. Ministério da Agricultura e Abastecimento. Diário Oficial da União, seção 1., $21 / 08 / 2001$.

CAMARGO, C.E.O.; FELICIO, J.C. Melhoramento genético do trigo no Instituto Agronômico. O Agronômico, Campinas, v.38, n.3, p.219-228, 1986.
CAMARGO, C.E.O.; OLIVEIRA, O.F. Tolerância de cultivares de trigo a diferentes níveis de alumínio em solução nutritiva e no solo. Bragantia, Campinas, v.40, n.1, p.21-31, 1981.

CAMPINAS, INSTITUTO AGRONÔMICO Recomendações Técnicas de Trigo para 1999. 2.ed.atual. Campinas, 1999. 100 p.

FELICIO, J.C., BARROS B. C.; CAMARGO, C. E. O.; BAR, W.H. Maracaí (IAC 17) e Xavantes (IAC 18) cultivares de trigo para o Estado de São Paulo. Bragantia, Campinas, v. 42,p. 15-25, 1983.

FELICIO, J.C., CAMARGO, C.E.O.; BARROS, B. C. Novos cultivares de Trigo (IAC 21- Iguaçu, IAC 22 - Araguaia, IAC 23 - Tocantins e IAC 24 Tucuruí). O Agronômico, Campinas, v.36, p. 147-151, 1984.

FELICIO, J.C.; CAMARGO, C.E.O., BARROS, B. C.; VITTI, P. Iguaçu (IAC 21) e Araguaia (IAC 22): Cultivares de trigo de sequeiro para o Estado de São Paulo. Bragantia, Campinas, v. 44 n.1,p.115-128, 1985.

FELICIO, J.C.; CAMARGO, C.E.O.; FERREIRA FILHO, A.W.P.; FREITAS, J.G.; BARROS, B.C. e VITTI, P. Tocantins (IAC 23) e Tucuruí (IAC 24): novos cultivares de trigo. Bragantia, Campinas,v.47, n.1,p. 93-107, 1988.

FELICIO, J.C.; CAMARGO, C.E.O-.; PEDRO JUNIOR, M.J.; FERREIRA FILHO, A.W.P. Avaliação de cultivares de trigo em duas regiões ecológicas do Estado de São Paulo. Pesquisa Agropecuária Brasileira, Brasília, v. 27, n. 9, p. 1245-1252, 1992.

FELICIO, J.C.; CAMARGO, C.E.O.; GERMANI, R.; MAGNO, C.P.R.S. Interação entre genótipos e ambiente na produtividade e na qualidade tecnológica dos grãos de trigo no Estado de São Paulo. Bragantia, Campinas, v.57 n.1,p.149$161,1998$.

FELICIO, J.C.; CAMARGO, C.E.O.; GERMANI, R.;GALLO, P.B.; PEREIRA, J.C.V.N.A.; BORTOLETTO, N.; PETTINELLIJUNIOR, A. Influencia do ambiente no rendimento e na qualidade de grãos de genótipos de trigo com irrigação por aspersão no Estado de São Paulo. Bragantia, Campinas, v.60, n.2, p.111120, 2001.

FELICIO, J.C.; CAMARGO, C.E.O-.; CASTRO, J.L. DE; GERMANI,R. Rendimento de grãos de trigo e sua relação com as doenças e variáveis climáticas em Capão Bonito de 1994 a 2001. Bragantia, Campinas, v.63, n.1,p. 93-103, 2004.

FERNANDES, J.M.; FERNANDEZ, M.R. Doenças das culturas sob manejo conservacionista. In: FERNANDES, J.M.; FERNANDEZ, M.R.; KOCHHANN, R.A.; SELLES, F.; ZENTNER, R.P. Manual de manejo conservacionista do solo para os Estados do Rio Grande do Sul, Santa Catarina e Paraná. Passo Fundo: EMBRAPA-CNPT / CNDA, 1991. P.53-58. (EMBRAPA-CNPT. Documento, 1)

HENRY SIMON LIMITED. Colorímetro Kent-Jones e Martin, série 2. Stock Port, Inglaterra, 1970.

ICC.INTERNATIONAL ASSOCIATION FOR CEREAL SCIENC AND TECHNOLOGY. ICC Standard Methods. Schwechat, Áustria, 1982. 
KERRIDGE, P.C. Aluminum toxicity in wheat (Triticum aestivum Vill.,Host). 1969, 170 f., Tese (Doutoramento).Oregon State University, Corvallis.

KOSMOLAK, F.G. Grinding time: A screening test for kernel hardness in wheat. Canadian Journal of Plant Science, Otawa, v.58,p.415-420, 1978.

MANDARINO, J.M.C. Aspectos importantes para a qualidade do trigo. Londrina, EMBRAPA-CNPSo, 1993. 32p. (Documento, 60)

METHA, Y.R. Doenças de trigo e seu controle. São Paulo, Agronômica Ceres, 1978. 190p., (Ceres, 20)

MOORE, D.P.; KRONSTAD, W.E. e METZGER, R.J. Screening wheat for aluminum tolerance. In: WORKSHOP ON PLANT ADAPTATIONS TO MINERAL STRESS IN PROBLEM SOILS, 1976. Beltsville, Maryland. Proceedings... Ithaca: Cornell University, 1976. p.287-295.

PICININI, E.C.; FERNANDES, J.M.C. Efeito de diferentes fungicidas sobre o rendimento de grãos, sobre o peso do hectolitro e sobre o controle da ferrugem da folha (Puccinia recondita f.sp. tritici) em trigo, cultivar BR 43. Fitopatologia Brasileira, Brasília, v.20, p.319, 1995. (Suplemento)

PICININI, E.C.; FERNANDES, J.M.C. Controle das doenças de trigo. In CUNHA, G.R.; BACALTCHUK, B. (Ed.). Tecnologia para produzir trigo no Rio Grande do Sul. Porto Alegre: Assembléia Legislativa, Comissão de Agricultura, Pecuária e Cooperativismo. Passo Fundo: Embrapa Trigo, 2000. p.225243. (Série Culturas, n. 02)
PEÑA, R. J.; ORTIZ-MONASTEIRO, J.I. e SAYRE, K.D Estrategias para mejorar (o mantener) la calidad panadeira en trigo de alto potencial de rendimento. In KOHLI, M. M.; D. Marino (eds.) 1998. Explorando Altos Rendimientos de Trigo. La Estanzuela, Uruguay: CIMMYT-INIA.octubre 20 al 23, 1997.

PIMENTEL-COMES, F. Curso de estatística experimental 4.ed.ver.ampl. Piracicaba, Nobel, 1970. 430p.

RAIJ, B. van; CANTARELLA, H.; QUAGGIO, J.A.; FURLANI, A..M. Recomendações de Adubação e calagem para o Estado de São Paulo. Campinas, Instituto Agronômico. Fundação IAC, 1996. 285p. (Boletim técnico 100)

SCHARAMM, W.; FULCO, W.S.; SOARES, M.H.G.; ALMEIDA, A.M.P. Resistência de cultivares de trigo em experimentos ou cultivo no Rio Grande do Sul, às principais doenças fúngicas. Agronomia Sulriograndense, Porto Alegre, v.10, p.31-39, 1974.

SILVA, A. R. Melhoramento das variedades de trigo destinadas às diferentes regiões do Brasil. Rio de Janeiro, Ministério da Agricultura, 82p. 1966. (Estudos Técnicos, 33)

SILVA, E.M.; LUCHIARI JUNIOR, A.; GUERRA. A.F.; GOMIDE, R.L. Recomendações sobre manejo de irrigação em trigo para a região dos cerrados. In: REUNIÃO DA COMISSÃO NORTEBRASILEIRA DE PESQUISA DE TRIGO. 10., 1984, Campinas. Anais... Brasília. EMBRAPA-CPAC, 1984.60p. 